\title{
Penerapan MRP Pada Persediaan Material Dan Pengaruhnya Terhadap Ketepatan Waktu
}

\author{
Gede Widya Jaya Laksana ${ }^{1)}$, I Gusti Agung Kade Suriadi'), I Putu Lokantara ${ }^{3)}$ \\ ${ }^{1,2,3)}$ Program Studi Teknik Mesin, Fakultas Teknik, Universitas Udayana \\ Kampus Bukit Jimbaran, Bali 80362 \\ Email: dedejayaa@gmail.com, suriadi@unud.ac.id, lokantara@unud.ac.id
}

doi: https://doi.org/10.24843/METTEK.2019.v05.i02.p09

\begin{abstract}
Abstrak
PT. X sudah dapat memproduksi kendaraan roda empat berkisar 300 buah/hari, pada saat penulis melaksanakan penelitian beberapa kali sempat terjadi bottle neck pada pos kerja perakitan engine sehingga hal tersebut menjadi dorongan bagi penulis untuk mencari tahu permasalahan yang sebenarnya sedang terjadi. Setelah melakukan observasi dan mewawancarai operator serta kepala staff yang bertugas pada assy-line mendapatkan hasil bahwa terhambatnya proses produksi tersebut dikarenakan terjadinya keterlambatan pada part yang dibutuhkan pada pos tersebut, maka dari itu dilaksanakan penelitian mengenai penerapan metode (MRP) material requirements planning, penelitian ini bertujuan untuk mengoptimalkan kinerja daripada suatu proses produksi material mentah menjadi bahan jadi yang bernilai jual tinggi, agar dapat terlaksana dengan tepat waktu dan dengan jumlah material yang tepat. Penelitian ini dilaksanakan dengan membuat master production schedule (MPS) atau jadwal induk produksi kemudian membuat catatan ketersediaan material dilanjutkan dengan membuat bill of material (BOM) atau struktur produk dari engine dan melakukan perhitungan peramalan permintaan menggunakan metode time series. Seluruh data yang telah diolah akan menjadi dasar dari pembuatan MRP, dengan jumlah produksi sebanyak 877 buah pada minggu ke-V Bulan April dan 864 buah pada minggu ke-I Bulan Mei menerapkan MRP pada suatu proses produksi dapat meningkatkan produktivitas kerja. Hasil perhitungan waktu yang didapat menunjukkan bahwa tidak terjadi bottle neck pada perhitungan MRP minggu ke-III, ke-IV dan ke-V.
\end{abstract}

Kata Kunci : Material Requirements Planning, MPS, Peramalan Permintaan.

\begin{abstract}
$X$ Inc. has been able to produce approximately 300 pieces of four-wheel vehicles per day, when the author carried out this research, there were some bottle necks happened several times on the work post of the engine assembly where it became a motivation for the author to find out what problems are going on. After observing and interviewing operator and chief of staff on the assy-line, it was concluded that the obstructed production process was caused by a delay in the needed parts on the said post, therefore a research about the application method of Material Requirement Planning (MRP) is carried out, where this research is aimed to optimize the production process of raw into finished, high valued materials, and can be done in a timely manner with exact amount of materials. This study was done by making a Master Production Schedule (MPS), then, making a material availability notation, continued by making a Bill of Material (BOM) and calculating the demand forecasting using the time series method. The entire data that had been processed became the base of the MRP-making, with the total production as many as 877 on the 5th week of April and 864 on the 1st week of May. Applying MRP on the production process can increase work productivity. The result of the time calculation obtained indicates that
\end{abstract}

Penulis korespondensi

Email: dedejayaa@gmail.com 
there was no bottle neck in the $3^{\text {rd }}, 4^{\text {th }}$, and $5^{\text {th }}$ week MRP calculation.

Keywords : Material Requirement Planning, MPS, Demand Forecasting

\section{PENDAHULUAN}

PT. X yang bertempat di Karawang selaku salah satu perusahaan yang berkembang dalam industri otomotif merupakan salah satu perusahaan strategis karena memiliki teknologi yang mampu bersaing dengan industri otomotif lainnya. Saat ini PT. X sudah dapat memproduksi kendaraan roda empat berkisar 300 buah/hari, pada saat penulis melaksanakan penelitian beberapa kali sempat terjadi bottle neck pada pos kerja perakitan engine sehingga hal tersebut menjadi dorongan bagi penulis untuk mencari tahu permasalahan yang sebenarnya sedang terjadi. Setelah melakukan observasi dan mewawancarai operator serta kepala staff yang bertugas pada assy-line mendapatkan hasil bahwa terhambatnya proses produksi tersebut dikarenakan terjadinya keterlambatan pada part yang dibutuhkan pada pos tersebut, maka dari itu dibalik padatnya jam kerja serta permintaan pelanggan yang harus dipenuhi dengan tepat waktu, permasalahan tersebut dapat diselesaikan dengan melaksanakan perencanaan produksi yang tepat salah satunya menggunakan metode Material Requirement Planning (MRP) dengan periode per produksi diketahui dalam satuan mingguan. Penerapan MRP dapat memberikan informasi kepada pihak perusahaan mengenai jumlah produksi pada part-part yang dibutuhkan sehingga proses produksi dapat berjalan dengan tepat waktu.

Rumusan masalah pada penelitian ini adalah Bagaimana mengendalikan kebutuhan material pada proses produksi engine NR pada PT. X agar jumlah material yang dibutuhkan sesuai dengan rencana produksi? dan Bagaimana merencanakan kebutuhan material pada proses produksi engine NR pada PT. X agar tepat waktu?

Tujuan penelitian ini adalah untuk menjamin jumlah material yang dibutuhkan sesuai dengan rencana produksi engine, Serta untuk merencanakan kebutuhan material dalam proses produksi engine tepat dengan waktu yang telah direncanakan.

\section{TINJAUAN PUSTAKA}

\subsection{Pengertian MRP}

Material Requirements Planning merupakan suatu teknik yang digunakan untuk penjadwalan, teknik tersebut pada umumnya digunakan oleh perusahaan manufaktur sebagai acuan untuk para pekerja yang terkait dengan alur dari suatu material. Teknik atau metode MRP khususnya membahas pada perencanaan suatu material, dikarenakan MRP secara umum merupakan teknik ataupun metode perencanaan dan penjadwalan. Metode MRP bisa disebut sebagai metode yang sangat sederhana namun pada kenyataan di lapangan dapat diketahui bahwa karena perencanaan dan penjadwalan inilah berhasil atau tidak suatu proses produksi itu.

\subsection{Tujuan Sistem MRP}

Metode MRP merupakan suatu sistem yang berfungsi untuk menghasilkan informasi yang akurat untuk melakukan tindakan selanjutnya dalam tahapan proses produksi (pembatalan pemesanan, pesan ulang dan penjadwalan ulang). Tindakan tersebut merupakan dasar dalam membuat keputusan mengenai pembelian atau produksi yang merupakan perbaikan atas keputusan yang telah dibuat sebelumnya.

Ada empat tujuan yang menjadi ciri utama sistem MRP, yaitu :

1. Menentukan kebutuhan material pada saat yang tepat

2. Menentukan kebutuhan minimal setiap material

3. Menentukan pelaksanaan perencanaan pemesanan

4. Menentukan penjadwalan ulang ataupun pembatalan atas suatu jadwal produksi yang sudah direncanakan sebelumnya. 
ojs.unud.ac.id/index.php/mettek

\subsection{Input Sistem MRP}

\subsubsection{Jadwal Induk Produksi}

Jadwal induk produksi merupakan suatu perencanaan yang mengidentifikasi kuantitas dari komponen tertentu yang didapatkan dan akan dibuat oleh suatu perusahaan manufaktur (dalam satuan waktu). Pada dasarnya JIP merupakan suatu pernyataan tentang produk jadi dari suatu perusahaan industri manufaktur yang merencanakan memproduksi output berkaitan dengan kuantitas dan periode waktu.

\subsubsection{Catatan Keadaan Persediaan}

Catatan keadaan persediaan merupakan suatu gambaran atas status komponen-komponen yang terdaftar pada persediaan. Pencatatan-pencatatan terhadap persediaan komponen itu harus terus dilaksanakan agar data yang diperoleh tetap up to date, dengan selalu melakukan pencatatan atas transaksi-transaksi yang terjadi, seperti penerimaan, pengeluaran, produk gagal dan lain sebagainya.

\subsubsection{Struktur Produk}

Input lain dalam membentuk MRP adalah struktur produk atau bill of material dari sebuah produk akhir yang ingin dibuat. Struktur produk merupakan rangkaian dari beberapa komponen yang digunakan untuk merakit suatu produk akhir. Struktur produk akan dipecah menjadi beberapa komponen-komponen dalam berbagai subassembly, dan bahan baku produk. Struktur produk berisi informasi tentang hubungan antara komponen satu dengan komponen lainnya dalam suatu proses perakitan. Informasi yang diperoleh dari struktur produk sangat penting dalam penentuan jumlah part atau komponen yang dibutuhkan pada setiap tahapan perakitan.

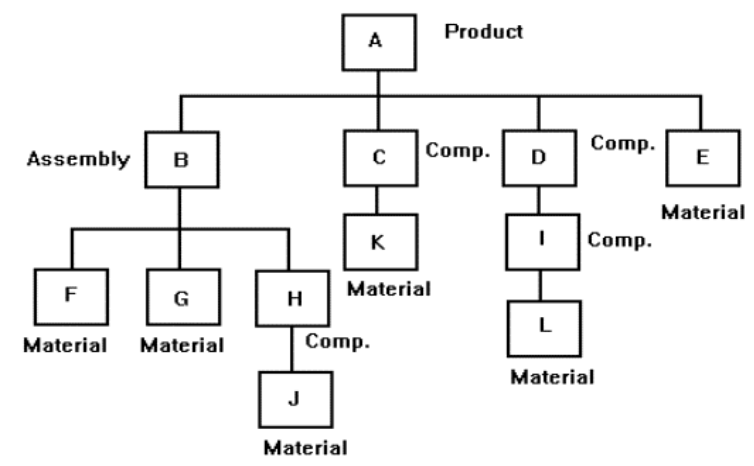

Gambar 1. Struktur Produk (Isnaini, 2011)

\section{METODE}

Metode penelitian yang digunakan dalam pengumpulan data adalah :

1. Metode Penelitian Kepustakaan (Library Research)

2. Metode Penelitian Lapangan (Field Research)

- Observasi, yaitu suatu metode dalam pengumpulan data dengan cara pengamatan langsung terhadap keadaan yang sebenarnya.

- Interview, yaitu suatu metode dalam pengumpulan data dengan cara mengajukan pertanyaan kepada pihak yang berwenang.

Langkah-langkah perhitungan MRP :

a. Mengumpulkan data riwayat permintaan periode sebelumnya.

b. Mengumpulkan data histori persediaan.

c. Membuat catatan keadaan persediaan.

d. Membuat jadwal induk produksi.

e. Membuat struktur produk. 
f. Menerapkan sistem MRP.

g. Perhitungan waktu untuk mengevaluasi bottle neck yang terjadi sebelum penerapan.

\section{HASIL DAN PEMBAHASAN}

\subsection{Struktur Produk Engine NR}

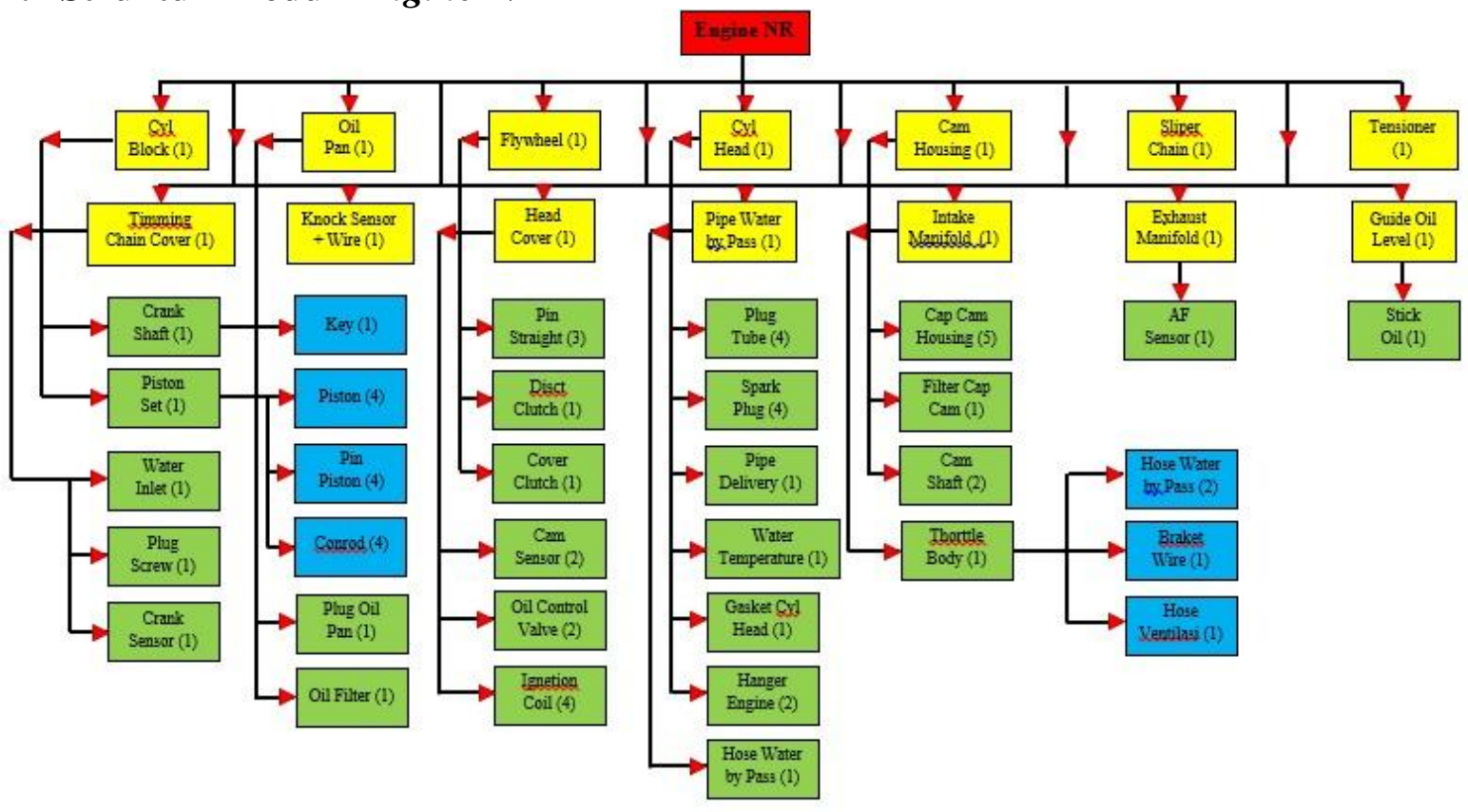

Gambar 2. Struktur Produk Engine NR

\subsection{Penerapan Sistem MRP}

Material Requirements Planning ini dibuat berdasarkan data-data diatas yang telah ditentukan oleh pihak perusahaan. PT. X berencana akan memproduksi engine sebanyak 877 buah pada minggu ke-V Bulan April dan sebanyak 864 buah pada minggu ke-I Bulan Mei, maka perhitungan MRP dapat dilakukan berdasarkan kebutuhan produksi tersebut. Item merupakan keterangan nama dari material yang akan diproduksi. On Hand merupakan status persediaan material yang dimiliki perusahaan pada stockroom disertai dengan informasi jumlah/kuantitas dari material tersebut dalam hal ini stock pada akhir minggu ke-III Bulan April 2019 
Tabel 1. Hasil Perhitungan MRP pada Engine

\section{MATERIAL REQUIREMENTS PLANNING}

\begin{tabular}{lcccccc} 
& \multicolumn{7}{l}{ Lot Size : 600} \\
\cline { 2 - 7 } Item : Engine & \multicolumn{7}{c}{ Time Periods (Weeks) } \\
\cline { 2 - 7 } $\begin{array}{l}\text { On Hand : } 20 \text { unit } \\
\text { Lead Time : } 1 \text { Week }\end{array}$ & 1 & 2 & 3 & 4 & 5 & 6 \\
\hline Kebutuhan Kotor & - & - & - & - & 877 & 864 \\
\hline Persediaan ditangan & - & - & - & 20 & - & - \\
\hline Kebutuhan Bersih & - & - & - & - & 857 & 864 \\
\hline Pelaksanaan Perencanaan Pemesanan & - & - & - & 857 & 864 & - \\
\hline
\end{tabular}

Tabel 2. Hasil Perhitungan MRP pada Cylinder Block

\section{MATERIAL REQUIREMENTS PLANNING}

\begin{tabular}{lcccccc} 
Item : Cylinder Block & \multicolumn{5}{c}{ Time Periods (Weeks) } \\
\cline { 2 - 7 } $\begin{array}{l}\text { On Hand : } 20 \text { unit } \\
\text { Lead Time : } 1 \text { Week }\end{array}$ & 1 & 2 & 3 & 4 & 5 & 6 \\
\hline Kebutuhan Kotor & - & - & - & 857 & 864 & - \\
\hline Persediaan ditangan & - & - & 20 & - & - & - \\
\hline Kebutuhan Bersih & - & - & - & 837 & 864 & - \\
\hline Pelaksanaan Perencanaan Pemesanan & - & - & 837 & 864 & - & - \\
\hline
\end{tabular}


Tabel 3. Hasil Perhitungan MRP pada Oil Pan

Lvl 1

\section{MATERIAL REQUIREMENTS PLANNING}

\begin{tabular}{lcccccc} 
& \multicolumn{7}{l}{ Lot Size : 600 } \\
\cline { 2 - 7 } Item : Oil Pan & \multicolumn{5}{c}{ Time Periods (Weeks) } \\
\cline { 2 - 7 } $\begin{array}{l}\text { On Hand : } 50 \text { unit } \\
\text { Lead Time : } 1 \text { Week }\end{array}$ & 1 & 2 & 3 & 4 & 5 & 6 \\
\hline Kebutuhan Kotor & - & - & - & 857 & 864 & - \\
\hline Persediaan ditangan & - & - & 50 & - & - & - \\
\hline Kebutuhan Bersih & - & - & - & 807 & 864 & - \\
\hline Pelaksanaan Perencanaan Pemesanan & - & - & 807 & 864 & - & - \\
\hline
\end{tabular}

Tabel 4. Hasil Perhitungan MRP pada Flywheel

MATERIAL REQUIREMENTS PLANNING

Lvl 1

\begin{tabular}{lcccccc} 
& \multicolumn{7}{l}{ Lot Size : 600 } \\
\cline { 2 - 7 } Item : Flywheel & \multicolumn{7}{c}{ Time Periods (Weeks) } \\
\cline { 2 - 7 } $\begin{array}{l}\text { On Hand : } 12 \text { unit } \\
\text { Lead Time : } 1 \text { Week }\end{array}$ & 1 & 2 & 3 & 4 & 5 & 6 \\
\hline Kebutuhan Kotor & - & - & - & 857 & 864 & - \\
\hline Persediaan ditangan & - & - & 12 & - & - & - \\
\hline Kebutuhan Bersih & - & - & - & 845 & 864 & - \\
\hline Pelaksanaan Perencanaan Pemesanan & - & - & 845 & 864 & - & - \\
\hline
\end{tabular}


Tabel 5. Hasil Perhitungan MRP pada Cylinder Head

Lvl 1

\section{MATERIAL REQUIREMENTS PLANNING}

\begin{tabular}{lcccccc} 
& \multicolumn{7}{l}{ Lot Size : 600 } \\
\cline { 2 - 7 } Item : Cylinder Head & \multicolumn{7}{c}{ Time Periods (Weeks) } \\
\cline { 2 - 7 } $\begin{array}{l}\text { On Hand : } 46 \text { unit } \\
\text { Lead Time : } 1 \text { Week }\end{array}$ & 1 & 2 & 3 & 4 & 5 & 6 \\
\hline Kebutuhan Kotor & - & - & - & 857 & 864 & - \\
\hline Persediaan ditangan & - & - & 46 & - & - & - \\
\hline Kebutuhan Bersih & - & - & - & 811 & 864 & - \\
\hline Pelaksanaan Perencanaan Pemesanan & - & - & 811 & 864 & - & - \\
\hline
\end{tabular}

\subsection{Perhitungan Waktu}

Perhitungan waktu berdasarkan pada level setiap item dimulai dari engine dengan kedudukan pada level 0 kemudian terdapat cylinder block, oil pan, flywheel, cylinder head, cam housing, timming chain cover, head cover, pipe water by pass, intake manifold, exhaust manifold, guide oil level dengan kedudukan pada level 1 yang memiliki material yang harus dirakit pada level 2 (dependent).

a. Waktu perakitan engine $=26$ menit

b. Waktu perakitan cylinder block $=4$ menit

c. Waktu perakitan oil pan $=2$ menit

d. Waktu perakitan flywheel $=2$ menit

e. Waktu perakitan cylinder head $=5$ menit

f. Waktu perakitan cam housing $=3$ menit

g. Waktu perakitan timming chain cover $=1$ menit

h. Waktu perakitan head cover $=3$ menit

i. Waktu perakitan pipe water by pass $=1$ menit

j. Waktu perakitan intake manifold $=3$ menit

$\mathrm{k}$. Waktu perakitan exhaust manifold $=1$ menit

1. Waktu perakitan guide oil level $=1$ menit

Keterangan : Total waktu yang tersedia $=2.160 \mathrm{jam}(129.600 \mathrm{menit}) / \mathrm{minggu}$.

Dimana mainline yang bertugas untuk merakit sebuah engine terbagi atas 18 pos dengan jam kerja dibagi menjadi 2 shift, shift pagi dimulai pada pukul 7.00 a.m. s/d pukul 6.00 p.m. (12 jam) dan shift malam dimulai pada pukul 7.00 p.m. s/d pukul 6.00 a.m. (12 jam), mesin produksi berhenti pada pukul 6.00 pagi dan sore serta pukul 12.00 siang dan malam. 
Tabel 6. Jadwal Perakitan

\begin{tabular}{|c|c|c|c|c|c|c|}
\hline Periode & I & III & IV & $\mathbf{V}$ & VI & Waktu/Item \\
\hline Engine & & & 857 & 864 & & 26 menit \\
\hline Cylinder Block & & 837 & 864 & & & 4 menit \\
\hline Oil Pan & & 807 & 864 & & & 2 menit \\
\hline Flywheel & & 845 & 864 & & & 2 menit \\
\hline Cylinder Head & & 811 & 864 & & & 5 menit \\
\hline Cam Housing & & 824 & 864 & & & 3 menit \\
\hline Timming & & 841 & 864 & & & 1 menit \\
\hline \multicolumn{7}{|l|}{ Cover } \\
\hline Head Cover & & 827 & 864 & & & 3 menit \\
\hline Pipe Water by Pass & & 767 & 864 & & & 1 menit \\
\hline Intake Manifold & & 826 & 864 & & & 3 menit \\
\hline Exhaust Manifold & & 841 & 864 & & & 1 menit \\
\hline Guide Oil Level & & 814 & 864 & & & 1 menit \\
\hline $\begin{array}{l}\text { Jumlah menit yang } \\
\text { diperlukan }\end{array}$ & & 21.401 & 44.746 & 22.464 & & \\
\hline
\end{tabular}

Pada minggu ke-III:

Waktu yang dibutuhkan $=(837 \times 4)+(807 \times 2)+(845 \times 2)+(811 \times 5)+(824 \times 3)+$ $(841 \times 1)+(827 \times 3)+(767 \times 1)+(826 \times 3)+(841 \times 1)+$ $(814 \times 1)=21.401$ menit atau 357 jam.

Sedangkan dengan total hari bekerja pada minggu ke-III sebanyak 5 hari memiliki total waktu yangtersedia 129.600 menit atau 2.160 jam, sehingga tidak terjadi bottle neck.

Pada minggu ke-IV:

Waktu yang dibutuhkan $=(857 \times 26)+(864 \times 4)+(864 \times 2)+(864 \times 2)+(864 \times 5)+$

$(864 \times 3)+(864 \times 1)+(864 \times 3)+(864 \times 1)+(864 \times 3)+$

$(864 \times 1)+(864 \times 1)=44.746$ menit atau 746 jam.

sedangkan pada minggu ke-V total hari bekerja sebanyak 2 hari dengan demikian memiliki total waktu yang tersedia 51.840 menit atau 864 jam. Sehingga tidak terjadi bottle neck pada minggu ke-IV.

$>$ Pada minggu ke-V:

Waktu yang dibutuhkan $=864 \times 26=22.464$ menit atau 374 jam

Waktu yang tersedia dengan total 2 hari bekerja pada minggu ke-VI sebesar 51.840 menit atau 864 jam, sehingga tidak terjadi bottle neck pada minggu ke-V. 
ojs.unud.ac.id/index.php/mettek

\section{SIMPULAN}

Berdasarkan hasil yang diperoleh dari penerapan material requirements planning dalam perencanaan produksi material diatas dapat diambil beberapa kesimpulan :

1. Material Requirements Planning dapat mengendalikan jumlah dari kebutuhan material pada proses produksi engine yang dilaksanakan pada minggu ke-IV, minggu ke-V dan minggu ke-VI sesuai dengan apa yang telah direncanakan.

2. Material Requirements Planning dapat merencanakan proses produksi engine sesuai dengan waktu yang direncanakan tanpa terjadinya bottle neck pada masing-masing minggu.

\section{DAFTAR PUSTAKA}

[1] Isnaini, 2011, Struktur Bill of Material, https://adagnitio.wordpress.com/2011/02/18/struktur-bill-of-material/. (20 Maret 2019)

[2] Nasution, Arman Hakim, 2003, Perencanaan \& Pengendalian Persediaan, Surabaya : Teknik Industri ITS.

[3] Nasution, Arman Hakim, 2006, Manajemen Industri, Yogyakarta : C.V. Andi Offset

[4] Penindra, I Made Dwi Budiana, 2015, Penerapan Material Requirements Planning Dalam Pengendalian Persediaan Bahan Baku Carded Fiber Pada PT. Hilon Indonesia-Bali, Volume 2, Nomor 1, Halaman 38-47. 